incidence of liver necrosis, it had no apparent effect on the depigmentation of the rats' incisors which takes place if these animals are fed on a diet deficient in tocopherol, and which is prevented only by this vitamin.

4. The parallelism between the effect of selenium and of vitamin E, both of which prevent liver necrosis and prolong the survival time of deficient rats, therefore does not extend to the disturbance causing dental depigmentation.

\title{
REFERENCES
}

Davies, A. W. \& Moore, T. (1941). Nature, Lond., 147, 794.

Himsworth, H. P. (1950). Lectures on the Liver and its Diseases, 2nd ed. Oxford: Blackwell.

Lindan, O. \& Himsworth, H. P. (1950). Brit. F. exp. Path. 31, 65 I.

Moore, T. \& Mitchell, R. L. (1955). Brit. F. Nutr. 9, 174.

Schwarz, K, \& Foltz, C. M. (1957). F. Amer. chem. Soc. 79, 3292.

Depigmentation of upper incisors in two rats fed on the 'necrogenic diet', supplemented with 20 p.p.m. sodium selenite, for 82 days. Whereas the lower incisors of the animal on the left are still normal in colour, they have become almost completely white in the animal on the right.

\section{Determination of the total daily energy expenditure in man by indirect calorimetry: assessment of the accuracy of a modern technique}

\author{
By J. V. G. A. DURNIN AND J. M. BROCKWAY \\ Institute of Physiology, University of Glasgow
}

(Received 8 May 1958-Revised 27 September 1958)

There have been several descriptions recently of experiments to determine, by indirect calorimetry, the total energy expenditure of human beings. With a few exceptions (for example, that of Booyens \& McCance (1957) who used the Douglas bag) these surveys have utilized the Max Planck respirometer (Kofranyi \& Michaelis, 1940; Müller \& Franz, 1952). This instrument was employed for measuring the energy expenditure of the various activities of the subjects, and the duration in time of each separate activity was also recorded. Some examples of such surveys are those of Lehmann, Müller \& Spitzer (1950); Passmore, Thomson \& Warnock (1952); Garry, Passmore, Warnock \& Durnin (1955); Durnin, Blake \& Brockway (1957); Welch, Marcinek, Buskirk \& Iampietro (1957); Brockett, Konishi, Brophy, Marcinek, Michalowicz, Grotheer \& Kashin (r957). The present paper is an attempt to assess the accuracy of such measurements.

There are several possible sources of error in determining the total energy expenditure of a human being living under normal everyday conditions, especially if the survey is of some days' duration and attempts to cover all $24 \mathrm{~h}$ of the day in contrast 
to the working time only. Some errors are difficult to detect since they may be due to inaccuracies in reporting the nature of activities and in timing the activities. Many sources of error, chiefly those in experimental technique, can be identified and often eliminated. In practice, the accuracy of the measurement of total energy expenditure by indirect calorimetry is uncertain. It is difficult to find another method, of which the accuracy is known, to compare with indirect calorimetry. For example, it is quite easy to compare the total food intake, assessed by some form of dietary survey, with the total energy expenditure: in theory, if the subject is in calorie balance, these two methods ought to yield the same results and give, therefore, some indication of accuracy. However, over a very short period of time, such as a few days, there is unlikely to be calorie balance and there may be a considerable variation between the food intake and the energy expenditure. Durnin (1957) has shown that there may be quite large differences (often $20-30 \%$ of the totals) between the calorie intake and the calorie expenditure of an individual on any one day; neither does the calorie intake seem to be related to the calorie expenditure of the previous day or to that of 2 days previously. In other words, if there is a delay in the regulation of balance between intake and expenditure, it does not obviously take place within this time. However, over a period of a week and longer, it is likely that the normal, healthy man living a steady, routine life is in approximate calorie balance. So that, by attempting to measure energy expenditure over this length of time and by comparing it with a careful quantitative assessment of the food intake, it is possible to find the degree of agreement between the two methods. If the agreement is good, confidence in both methods is enhanced.

So far, there has been no complete detailed description of the possible inaccuracies in the technique of indirect calorimetry with the Max Planck respirometer, though some aspects of this problem have been mentioned by several authors. Orsini \& Passmore (I95 I) made a comparison between the results obtained with a Douglas bag and those obtained with the old-type Kofranyi-Michaelis respirometer. Passmore \& Durnin (I955) discussed briefly the importance of exact measurement of the times spent in the different activities of the subject during the day relative to the accuracy of the actual measurement of the energy expenditure, for a few minutes, during these different activities. There have been three very instructive articles from the U.S. Army Medical Nutrition Laboratory. Insull (1954) described in detail the difficulties in the use of the newer model of respirometer. Rankin, Konishi, Insull \& Marcinek (1956) compared the use of mouthpieces and of face masks. These did not affect the results. Over periods of approximately $2 \mathrm{~h}$ they also estimated the total energy expenditure by the continuous measurement of oxygen consumed and by the factorial (or timemotion) method, which consists of multiplying the length of time spent in each activity by the measured energy expenditure (in Cal./min) of the particular activity, the final sum giving the total energy expenditure. The end results of these two methods of calculation were not significantly different. Brockett et al. (1957) concluded, from a study of eight soldiers over 2 weeks, that the diary method of recording activities by the individual subject (Garry et al. 1955) gave results closely similar in accuracy to those obtained by having these varied activities watched and exactly 
timed by observers. A recent paper (Montoye, van Huss, Reineke \& Cockrell, r958) deals with the capabilities of the Max Planck respirometer under the name of the 'Müller-Franz calorimeter', which is an air-meter and can almost justifiably be called a respirometer but is certainly not a calorimeter. These authors measured the calibration factors of some of these meters by a method based on that described by Durnin (1955). In contrast, however, they used only a steady flow of air and not a pulsatile flow as in normal breathing. Their results differ considerably from our own; most of their instruments were quite unusable at flow rates equivalent to a pulmonary ventilation of $40-501 . / \mathrm{min}$. This difference may have been due to absence of proper maintenance of the meters.

The present paper gives, in fairly full detail, an account of the practical use of the respirometer and of the difficulties of assessing energy expenditures by indirect calorimetry. The procedure is illustrated by reference to a week's experiment on four young men when the expenditure of energy was measured by indirect calorimetry and the total food intake was accurately measured during the same period.

\section{METHODS}

\section{Subjects}

Physical details of the four subjects are given in Table $\mathrm{r}$. The subjects were young male students all trained in the use of the various pieces of apparatus.

Table I. Physical characteristics and theoretical B.M.R. of the four male subjects

$\begin{array}{lcccc}\text { Subject } & \begin{array}{c}\text { Age } \\ \text { (years) }\end{array} & \begin{array}{c}\text { Height } \\ (\mathrm{cm})\end{array} & \begin{array}{c}\text { Weight } \\ (\mathrm{kg})\end{array} & \begin{array}{c}\text { B.M.R. } \\ \text { (Cal./min) }\end{array} \\ \text { McG. } & 23 & 182 & 78 \cdot 0 & 1 \cdot 27 \\ \text { McK. } & 21 & 164 & 62 \cdot 5 & 1 \cdot 08 \\ \text { P. } & 20 & 175 & 65 \cdot 5 & 1 \cdot 15 \\ \text { R. } & 21 & 178 & 68 \cdot 0 & 1 \cdot 18\end{array}$

\section{Measurement of food intake}

The total food intake of each subject was measured daily by the individual-inventory method, each article of food being separately weighed and recorded. It was impressed on the men that they must not alter their normal diet because of the survey: it is almost certain that little or no alteration took place. Details of the methods are more fully described in an earlier study (Garry et al. 1955). Records were checked each day so that there was little scope for misunderstanding during the study. Any extra food bought outside the home was always in the form of standard, packaged proprietary items, and their exact quantities were obtained by buying similar articles and weighing them. Plate waste was deducted from the original weight of the food. The energy value and the proportions of protein, fat and carbohydrate, as well as the mineral and vitamin contents, were estimated from tables supplied by the Ministry of Agriculture, Fisheries and Food. The nutrient-conversion factors in these tables are based largely on those compiled by the Medical Research Council (1945) with some alterations to 
adjust the values for recent changes in the composition of foods. Some uses of these tables are discussed by Garry et al. (1955). The food eaten by each individual was calculated separately for each of the 7 days.

\section{Measurement of energy expenditure}

The assessment of the total daily energy expenditure was made by the factorial method; that is, each subject kept a detailed record of the time spent in each of the various daily activities, and the metabolic cost of certain of these activities was measured by indirect calorimetry with the Max Planck respirometer. The minute-byminute record of activities was kept in special notebooks in the simplified form detailed by Garry et al. (1955). These records were kept meticulously over the week and are probably a very accurate estimate of the length of time spent each day in the different forms of everyday activity. The energy expenditures were measured on several different occasions with each subject while sitting, standing and walking at normal speed. The calorie cost of lying in bed was assumed to be approximately equal to the basal metabolic rate calculated by the method of Fleisch (195 I) (cf. Passmore \& Durnin, 1955), and that of dressing was taken as $\mathrm{I} \cdot 9$ times the value obtained for standing (Passmore et al. 1952; Garry et al. 1955). Other figures were from the tables of Passmore \& Durnin (1955). The respirometers were calibrated frequently by the method described in the appendix. The total energy expenditure was calculated by multiplying the number of minutes spent in each activity by the calorie value of that activity and the totals were added together to cover all the activities of each individual day.

It is probably not sufficiently realized that Max Planck respirometers can be used satisfactorily only if they are regularly serviced and frequently calibrated. With proper calibration these instruments are accurate and are still probably the simplest and most convenient for use in this type of investigation. The methods used in calibration and in maintenance are described in some detail in the appendix.

\section{RESULTS}

The mean daily calorie intakes and expenditures are shown in Table 2. Also given are the mean times spent each day in the various activities and their calorie equivalents. Measurements of the energy expenditures while sitting, standing and walking are shown in Table 3 .

The discrepancy between the mean daily calorie intake and expenditure was approximately $9 \%$ for the subject McG., $6 \%$ for McK., $17 \%$ for P. and $\mathrm{I} \%$ for R. These differences were not always in the same direction, that is the energy intake was not uniformly higher or lower than the energy expenditure.

\section{DISCUSSION}

The sources of error in an experiment such as this may be considered under several headings. The difficulties in estimating the dietary intake have been mentioned by several authors (Food and Agriculture Organization of the United Nations, 1949; Hollingsworth, 1955; Merrill \& Watt, 1955; Durnin, 1958; and others). Inaccuracy 
in the assessment of energy expenditure may be due to $(a)$ errors in the recording of the duration of the separate activities; $(b)$ failure to define the activity accurately; (c) errors in the technique of measuring the metabolic cost of an activity; $(d)$ failure of the subject to behave in typical fashion while the expenditure of energy is being measured. Over and above these sources of error, there is also the possibility that the subject may digress from his normal general routine because of the experiment. In comparing food intake and energy expenditure it should also be remembered that throughout the experiment the subject may not be in physiological equilibrium: he may be taking in more energy than he expends or vice versa.

Table 2. Mean daily length of time on different activities and energy expenditure of the four male subjects

\begin{tabular}{|c|c|c|c|c|c|c|c|c|}
\hline \multirow[b]{2}{*}{ Activity } & \multicolumn{2}{|c|}{ McG. } & \multicolumn{2}{|c|}{ McK. } & \multicolumn{2}{|c|}{ P. } & \multicolumn{2}{|c|}{ R. } \\
\hline & Min & Cal. & Min & Cal. & Min & Cal. & Min & Cal. \\
\hline In bed & 592 & 752 & 513 & 554 & 515 & 592 & 507 & 598 \\
\hline Washing, dressing and the like & 34 & I 16 & 29 & $9 \mathrm{I}$ & 18 & 68 & 23 & 76 \\
\hline Sitting & 599 & 1090 & 605 & 865 & 564 & II 34 & $55^{6}$ & rorg \\
\hline Standing & 58 & I 49 & 116 & 190 & $9^{\circ}$ & 177 & 157 & 267 \\
\hline Walking: normal & 121 & 998 & 134 & 847 & $13^{\circ}$ & 898 & 142 & 1057 \\
\hline slow & 23 & 69 & 12 & 47 & 112 & 613 & 22 & 99 \\
\hline Miscellaneous* & 13 & 71 & $3 \mathbf{I}$ & 88 & I $\mathrm{x}$ & 57 & 33 & 132 \\
\hline Total & & 3245 & & 2682 & & 3539 & & 3248 \\
\hline Mean daily intake & & 2953 & & 2847 & & 2939 & & 3290 \\
\hline
\end{tabular}

Table 3. Energy expenditure (Cal./min) of each subject during the common 'activities'

$\begin{array}{lccc}\text { Subject } & \text { Sitting } & \text { Standing } & \text { Walking } \\ \text { McG. } & \mathbf{1} \cdot 82 & 2 \cdot 56 & 8 \cdot 27 \\ \text { McK. } & \mathbf{1} \cdot 43 & \mathbf{1} \cdot 62 & 6 \cdot 32 \\ \text { P. } & 2 \cdot 01 & \mathbf{1} \cdot 97 & 6 \cdot 90 \\ \text { R. } & \mathrm{I} \cdot 83 & \mathbf{I} \cdot 70 & 7 \cdot 46\end{array}$

The first- and last-mentioned errors ( $a$ and $d$ ) can be largely eliminated by the proper psychological approach in explaining to the subject the purpose of the experiment. It is extremely important to impress on the subject the necessity for accuracy in the recording of the different things done throughout the day and also to try to prevent such recordings having an undue effect on his normal everyday life. From our own experience, frequent contact with the participants in the experiment--they should be visited regularly at least once a day-can minimize this source of inaccuracy. In the particular experiment described here the subjects were university students of physiology in their final Honours year and therefore probably above average in intelligence and co-operation; hence errors due to this source were minimal. None the less, it is impossible for a subject to record activities that take up on any one occasion less than I min. In other words, if there is a considerable time during the day when the subject may be standing around making occasional movements lasting only a few seconds, it is difficult to be certain that the total estimate obtained for the duration of these movements is accurate. Part of this error may be minimized if these short-term movements are consistent enough and occur frequently enough for their extent to be 
measured by the experimenter, as can be done during working hours when the subject can be observed. Such observation is impracticable in the home, and it is impossible to be sure to the minute of the accuracy of this record of activities. For instance, the subject may be sitting down and suddenly decide to fetch a book or newspaper from the other side of the room, or switch on the wireless, or pick up something from the floor, or make any of the movements that occur frequently and irregularly, but do demand quite considerable momentary increases in the expenditure of energy.

It must also be remembered that the record of daily activities must be made in a simple form in order to minimize the onus on the subject. It means that, in large-scale field work, it is impossible to expect anyone to record his activities other than simply, for example, as sitting, standing or walking; it is too difficult to note whether, for example, the subject is sitting reading or sitting writing, standing quite still or standing with occasional movements, and so on. With the less energetic activities (such as lying, sitting, or standing) the error from these causes in estimates of expenditure is probably small. For instance, if a measurement of the energy expenditure of a subject while sitting gave a value which differed by even as much as $0.3 \mathrm{Cal} . / \mathrm{min}$ from the actual mean energy cost of sitting, then the total error during a normal day, when sitting might occupy about $500 \mathrm{~min}$, would be I 50 Cal. Similar, though smaller, errors might occur with lying and standing. However, the more measurements carried out on each activity under 'ordinary' conditions, the smaller will be the error. In any event, even with single measurements of separate activities, it is improbable that the error will be consistently above or below the true mean. It would thus appear that such errors might be self-cancelling in their effects, especially when the investigation lasts for several days. It is possible, however, to introduce greater errors with activities of some hours' duration and requiring much expenditure of energy. For example, in this experiment the subjects recorded their walking as 'normal' or 'slow'. An inexact definition of such an activity might cause an appreciable error in calculating the energy expenditure of walking.

Inaccuracy may well result from unskilled use of the apparatus. Errors in the use of the Douglas bag in the laboratory have been described fairly fully by Shephard (1955). In practice outside the laboratory, these difficulties with the Douglas bag may be increased since the apparatus is rather bulky and the bag almost certainly interferes to some extent with normal activity. The bag's capacity (roo 1.) also limits the amount of expired air which can be collected from the subject. Many of the ways in which errors can arise in the use of Max Planck respirometers have been described by Insull (1954) and by Rankin et al. (1956). The use of these respirometers requires considerable care. There have been marked differences among the eight or nine used for fairly lengthy periods by us in this laboratory. The correction factors of each machine may vary by several per cent depending upon the rate of flow, and they must be calibrated over the complete range of flow rates at which they will be used. The resistance to the air-flow also varies remarkably with different Max Planck respirometers; some should not be used when the pulmonary ventilation is more than $301 . / \mathrm{min}$, whereas others may be quite satisfactory at twice this rate. 
The measured energy cost of the various activities may not truly represent those activities actually recorded in the time-motion study and this error is closely related to the error referred to under $(b)$, i.e. errors due to failure to define the activity accurately, which may be conveniently illustrated for 'walking'. There may be a very large variation in the energy expenditure of what may be recorded as 'walking' by any one individual. To be reasonably exact, if much time is spent in this activity, walking should be subdivided into two or three categories and measurements made of the energy expenditure appropriate to each type. It is very probable that, in our experiment, the values allotted to walking did not always represent the actual energy expenditure of the subject while walking. Since each subject spent a comparatively large amount of time 'walking', this error may largely account for the difference between total energy intakes and expenditures.

It may sometimes be very difficult to persuade the subject to act in a normal representative manner while wearing the apparatus. Except in rare instances this difficulty should be overcome by practice. Also, it may not always be ascertainable whether or not a measurement of the energy expenditure during, for instance, standing, gives a true indication of the energy expenditure while standing at other times in the day. Probably the only corrective is to obtain several measurements of the important activities at different times of the day and on different days.

We have already stated in the introduction that healthy people, leading a normal routine life, are likely to be in approximate calorie balance over a period of 7 days. In a fairly large group, it might be expected that the effects of individual deviations from calorie balance would tend to be minimized. An attempt was therefore made to obtain an estimate of the expected amount of the difference between mean energy intake and mean energy expenditure for any individual when these were measured over a period of 7 consecutive days. This was done by analysing the data available from five separate surveys, all conducted by the same technique. By this means, values were obtained for seventy-eight individuals (thirty-three women and forty-five men) from the following sources:

4 men (this study);

29 men (clerks and miners, Garry et al. 1955);

I2 men (military cadets, Edholm, Fletcher, Widdowson \& McCance, 1955);

24 women (housewives and daughters, Durnin et al. 1957);

9 women (elderly; recent unpublished values from this laboratory).

Fig. I shows the values of energy expenditure plotted against energy intake for these seventy-eight persons. The regression line, derived from all seventy-eight individuals, intercepts the vertical axis at a point significantly different from the origin. There was no significant difference in the slopes of the regression lines derived separately for the men and for the women. The actual regression equations were:

$$
\begin{array}{ll}
\text { For all } 78 & E=0.566 I+\text { I I } 77, \\
\text { For the } 45 \text { men } & E=0.510 I+\text { I } 545, \\
\text { For the 33 women } & E=0.485 I+\text { I I } 7,
\end{array}
$$

where $E$ and $I$ are the mean energy expenditure and energy intake in Cal. respectively. 
The separate product-moment correlation coefficients were:

$r=0.69$ for all subjects,

$r=0.6_{3}$ for the men,

$r=0.64$ for the women.

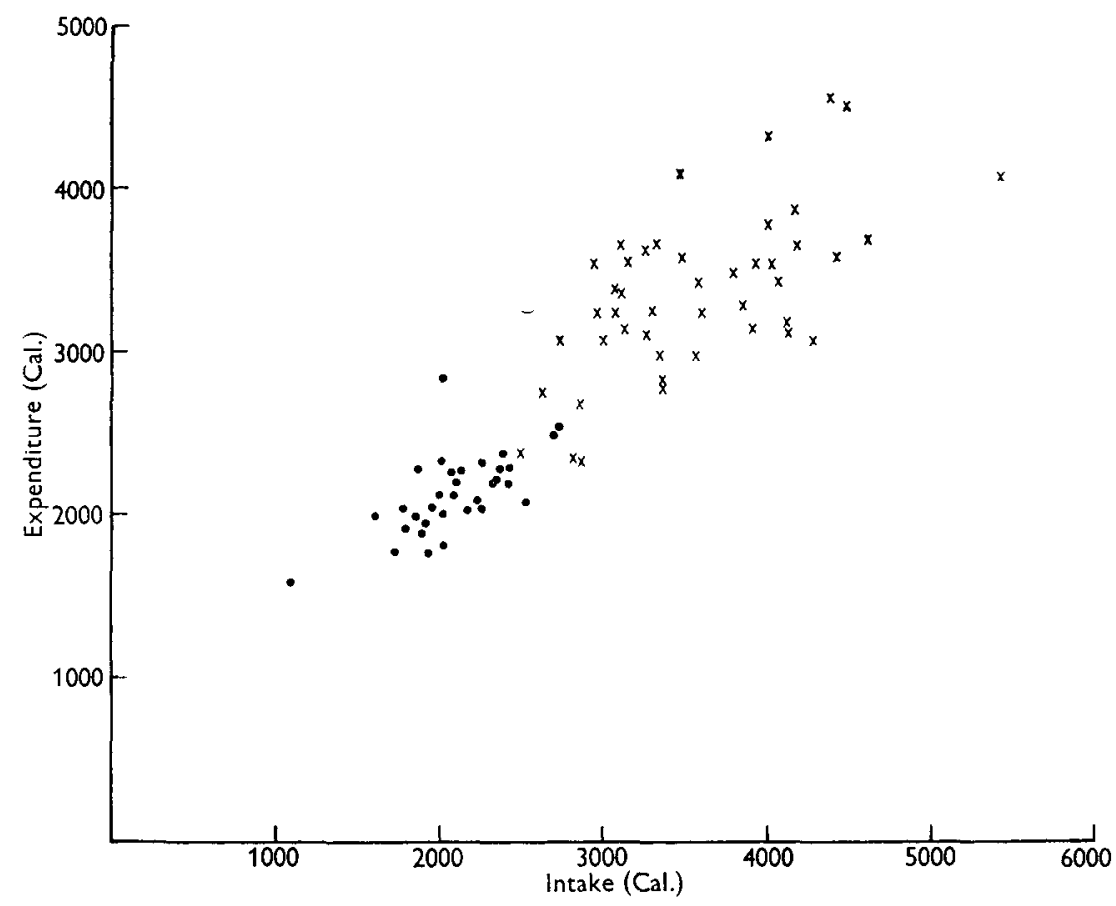

Fig. I. Mean daily values of energy expenditure plotted against energy intake for seventy-eight subjects (thirty-three women and forty-five men). $\times$, men; $\bullet$, women.

For all seventy-eight individuals, the mean difference, when the expenditure (mean $=2839$ Cal.) was subtracted from the intake, was $+98 \mathrm{Cal}$, and the standard deviation of the differences $425 \mathrm{Cal}$. On the assumption that approximately $95 \%$ of all the individual differences lie within the range $98 \mathrm{Cal} . \pm$ twice the standard deviation $=98 \pm 850 \mathrm{Cal}$., then these differences should lie between $-75^{2}$ and $+948 \mathrm{Cal}$. The mean difference, $98 \mathrm{Cal}$., was significantly different from zero.

For the thirty-three women (mean expenditure 2130 Cal.), the difference was -42 Cal., and the range was $-42 \pm 510 \mathrm{Cal}$; that is $95 \%$ of all the differences should lie between $-55^{2}$ and $+468 \mathrm{Cal}$. The value -42 Cal. was not significantly different from zero.

For the forty-five men (mean expenditure 3360 Cal.), the respective values were $+201 \pm 985 \mathrm{Cal}$. The differences should therefore lie between -784 and +1 I $86 \mathrm{Cal}$., and 201 Cal. was significantly different from zero.

Quite clearly one can expect a considerable discrepancy between the determinations of energy expenditure and of energy intake by an individual when these determinations are made by the methods used here. It is a moot point at present which is the more 
accurate determination. The considerable size of the differences should be kept constantly in mind.

In field work of this nature it is important to be continually aware of all the possible errors when attempting to measure total energy expenditure and food intake. At the present time we are rather apt to ignore the errors inherent in dietary surveys and to accept uncritically the determination of energy intake as a standard of reference for determinations of energy expenditure. Many quite erroneous conclusions are arrived at when authors do not properly appreciate the reliance that can be placed on their methods and results. Few surveys indeed are carried out with the maximal accuracy of which the method is capable. The actual error in the determination of expenditure by indirect calorimetry, from our own experience and from that of other workers, may be conservatively estimated to be at least $5 \%$. It means that the error, when the total energy expenditure is around $3000 \mathrm{Cal}$., is about $150 \mathrm{Cal}$., and with $2000 \mathrm{Cal}$. it is about $100 \mathrm{Cal}$. It is, therefore, usually meaningless to indulge in elaborate discussion of the reasons for differences of less than this amount, especially when the experimental period can be, at best, but a relatively short period of time in terms of total metabolism.

\section{SUMMARY}

I. The various sources of error in measurements of total energy expenditure in the field are discussed in relation to a small experiment in which the food intake and energy expenditure of four young men were measured for $\mathrm{I}$ week.

2. These errors may be due to $(a)$ faulty recording of the duration of separate activities; (b) inexact definition of the activity; $(c)$ technical difficulties in measuring the metabolic cost of an activity; $(d)$ failure of this last activity to represent the normal activity noted on the time-motion diary record. There may also be disturbance of the subjects' normal daily routine because of the experiment.

3. A statistical analysis was done on the results from determinations by different authors of the energy expenditure and of energy intake of a total of seventy-eight individuals. The correlation coefficient $(r=0.69)$ and mean difference $(+98 \mathrm{Cal}$.) with standard deviation ( 425 Cal.) of these two variables are given for the seventyeight subjects (thirty-three women and forty-five men). These statistical results were also analysed separately for the men and for the women. The values were: for men $r=0.63$ (difference +201 Cal., S.D. 493 Cal.); for women $r=0.64$ (difference -42 Cal., S.D. 255 Cal.).

4. A suitable technique for calibrating and maintaining Max Planck respirometers is described in an appendix.

We are grateful to Dr R.A. Robb of the Statistics Department, University of Glasgow, for assistance and to Professor R. C. Garry for advice. This work is part of a research programme supported by the Scottish Hospital Endowments Research Trust. 
APPENDIX

\section{General maintenance and calibration of the Max Planck respirometer}

Maintenance. The mechanism of the pump and counter is accessible after removal of the top cover of the meter. The pump mechanism for sampling the expired air should be lubricated periodically with light oil. This attention is important since much of the resistance of the respirometer is due to the pump. Its rubber membranes and connecting tubing should be inspected from time to time and replaced when necessary. The rotating valve plates of the pump should also be inspected frequently to ensure that they are clean and seat evenly: a light film of oil should be applied occasionally to the inner faces of these plates. The mechanism of the Veeder counter is simple, and no trouble has been experienced with it.

The bellows and their cranks are sealed in the lower part of the meter and it is inadvisable to disturb them. After prolonged use the bottom of the lower casing may become corroded and even perforated. Should it happen, the meter must be discarded or repaired. A sheet of thin copper or brass can be soldered over the bottom of the casing if the corroded area is large, or small holes may be soldered individually. After each period of use the condensed moisture should be drained from inside the bellows, otherwise water will accumulate with consequent upset to the meter's accuracy.

We experienced trouble with badly soldered joints, particularly with that of the sample-tap block. The connexions between the valve crank-levers and the vertical shafts from the bellows are also liable to give way. If the meter has to stand up to rough treatment, it is worth while changing the 'disengage-counting' lever as described by Insull (1954) or by Garry et al. (1955).

Calibration. The respirometers are calibrated by the makers, and the correction factor (K.F.) is engraved on the window of the counter. We have never yet found this calibration to be accurate, and users of the respirometer should ignore this factor and re-calibrate the apparatus for themselves. It is essential that the meters be calibrated with an air flow of the same pattern as that encountered in use; i.e. the air flow should be pulsatile at physiological respiration frequencies $(12-60 / \mathrm{min})$, and also should cover the range of flow rates encountered in normal human pulmonary ventilation $\left(5^{-} \mathrm{I} 00 \mathrm{l}\right.$./ $\min )$.

Durnin (1955) described a system of calibration in which a pulsatile flow, simulating normal respiration, was produced from a Douglas bag. This method is rather difficult and laborious to use though the apparatus required is simple. An alternative method has been evolved, based on that of Durnin and also on that of Wolff (1958). The apparatus is shown in Fig. 2. It consists of: (I) A blower capable of delivering a steady flow of up to about $500 \mathrm{l} . / \mathrm{min}$ (a vacuum cleaner used 'in reverse' is ideal for this purpose). (2) A motor-driven interrupter fan, which consists of a low-geared constant speed ( $12 \mathrm{rev} . / \mathrm{min}$ ) electric motor and a set of five interchangeable fans. These fans have alternate regular segments cut out (see Fig. 2) and allow the air stream to be interrupted $\mathrm{I2}, 24,36,48$ or 60 times/min. Used in conjunction with I in. bore tubing, they produce an air-flow pattern roughly similar to that of normal respiration. Alternatively, a variable-speed motor with a single fan can be used. A shutter to 
control the volume of flow is mounted on the same unit as the interrupter fan. It operates, guillotine-wise, in a slot across the air-supply tubing and is used to regulate the volume of air passing through the system. (3) A large 'standard' gas meter; a refined version of a commercial bellows gas meter has been found to be consistently accurate in its measurements at the required flow rates. This 'standard' meter is periodically re-calibrated by the makers (Parkinson \& Cowan Ltd).

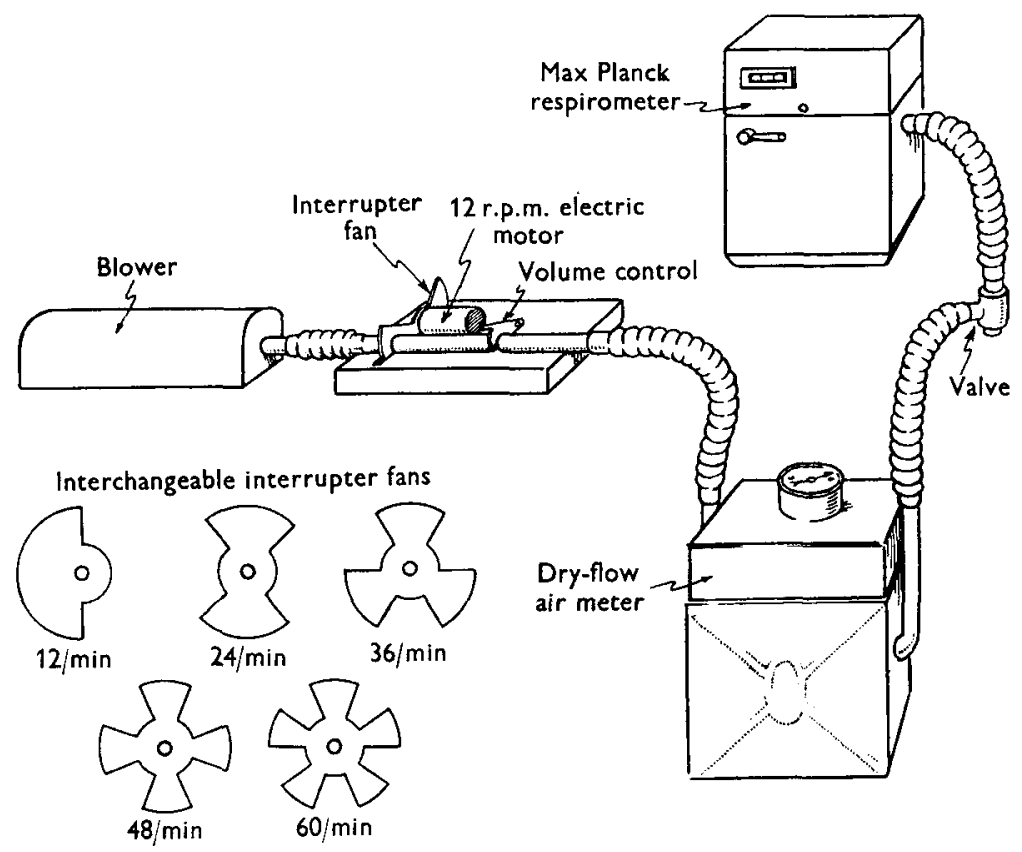

Fig. 2. Apparatus for calibration of Max Planck respirometers.

Calibration is carried out by connecting this apparatus in series with the respirometer under test, through a valve and length of tubing as in actual use. By using the volume control in conjunction with the appropriate fan (see Table 4) the rate of air flow in the system is first adjusted to approximately $5 \mathrm{l} / \mathrm{min}$, as measured on the 'test' meter. With the blower still running, the interrupter fan is stopped, so as to cut off completely the air flow to the meters. Readings are taken on the 'standard' and on the 'test' meters. The interrupter fan is re-started and a total volume of $20-301$. of air is allowed to pass through the system, and the fan is stopped (again so as to

Table 4. Simulated respiratory rate at different flow volumes in the Max Planck respirometer

$\begin{array}{cc}\begin{array}{c}\text { Volume of flow } \\ (1 . / \mathrm{min})\end{array} & \begin{array}{c}\text { Interruptions/ } \\ <20\end{array} \\ \begin{array}{c}<2 \\ 20-50\end{array} & 24 \\ 50-70 & 36 \\ 70-100 & 48 \\ >100 & 60\end{array}$


cut off completely the air flow). Readings are taken on both meters and the process is repeated. The correction factor is calculated thus:

Volume passed through standard meter $=20.01$.,

Volume recorded on respirometer $=18.51$,

Therefore correction factor $($ at $51 . / \mathrm{min})=\frac{20 \cdot 0}{18 \cdot 5}=\mathrm{r} \cdot 08$.

The mean of two calibrations is taken as the correction factor of the respirometer at the particular flow rate used.

The flow rate of the system is then readjusted to approximately $101 . / \mathrm{min}$, and the calibration and calculation are repeated but with, of course, a correspondingly greater total flow of air. The respirometer is similarly calibrated at higher flow rates, but now at $101 . / \mathrm{min}$ intervals, up to the highest likely to be met with (for moderate exercise and work it will probably not exceed $501 . / \mathrm{min}$ ). Should any large changes occur in the correction factor with flow rates at intervals of $101 . / \mathrm{min}$, factors should be determined for intermediate rates of flow. A calibration chart (Table 5 ) is thus prepared for each respirometer in use.

Table 5. Sample table of correction factors for the Max Planck respirometer at different flow volumes

$\begin{array}{cc}\begin{array}{c}\text { Respirometer no. ...... } \\ \text { Volume of flow } \\ (1 . / \mathrm{min})\end{array} & \begin{array}{c}\text { Date } \ldots / \ldots / \ldots \ldots \\ \text { Correction } \\ \text { factor }\end{array} \\ 5 & \mathrm{1} \cdot 08 \\ 10 & 1.07 \\ 20 & 1 \cdot 05 \\ 30 & 1.06 \\ 40 & 1 \cdot 06 \\ 50 & 1.07 \\ 60 & 1.08\end{array}$

To find the corrected pulmonary ventilation, the volume recorded by the respirometer is multiplied by the correction factor appropriate for the recorded flow rate. For example, if the respirometer had recorded a volume of $200 \mathrm{l}$. during to min, and if the correction factor for a flow of $201 . / \mathrm{min}$ were $\mathrm{I} \cdot 05$, the true pulmonary ventilation during that period would be:

$$
\frac{200}{10} \times \mathrm{I} \cdot 05=2 \mathrm{r} 1 . / \mathrm{min} \quad(\text { Table } 5) \text {. }
$$

This figure would then be adjusted to s.t.p. or to B.T.P.s. (body temperature and pressure, saturated).

The calibration of respirometers in use should be checked daily. The correction factor has been found frequently to change by more than $\mathrm{I} \%$ from day to day even with the respirometer apparently working perfectly. Owing to various defects, frictional or corrosive, much larger changes may occur which can easily pass unnoticed if such frequent calibration is not carried out.

Effect of temperature. The temperature of the expired air passing through the respirometer is recorded on a thermometer mounted in its upper cover. This is the 
temperature of the outlet side of the meter which may, in certain circumstances, be considerably lower than that of the inlet side. The error thus introduced into the assessment of pulmonary ventilation when adjusted to standard temperature and pressure is usually quite small. $\mathrm{A}_{4}{ }^{\circ}$ drop in temperature across the meter causes an error of a little more than $\mathrm{r} \%$ and a $10^{\circ}$ drop causes an error of about $4 \%$ in the calculation of the pulmonary ventilation. The temperature drop across the meter used indoors will rarely be as large as $4^{\circ}$ though out-of-doors in cold weather the drop may well exceed $10^{\circ}$. If the meter is to be used in such conditions it may be worth while to fit an additional thermometer on the inlet side of the meter and to adjust the determination of the pulmonary ventilation by use of the mean temperature of the two thermometers.

\section{REFERENCES}

Booyens, J. \& McCance, R. A. (1957). Lancet, 272, 225.

Brockett, J. E., Konishi, F., Brophy, E. M., Marcinek, J. G., Michalowicz, W. A., Grotheer, M. P. \& Kashin, P. (1957). U.S. Army. Med. Nutr. Lab. Rep. no. 212.

Durnin, J. V. G. A. (1955). F. Physiol. 128, 294.

Durnin, J. V. G. A. (1957). F. Physiol. 136, $34 P$.

Durnin, J. V. G. A. (1958). Diététique et Nutrition, 9, no. 3, p. 2 I.

Durnin, J. V. G. A., Blake, E. C. \& Brockway, J. M. (1957). Brit. F. Nutr. I1, 85.

Edholm, O. G., Fletcher, J. G., Widdowson, E. M. \& McCance, R. A. (1955). Brit. F. Nutr. 9, 286.

Fleisch, A. (195I). Helv. med. acta, 18, 23.

Food and Agriculture Organization of the United Nations (1949). F.A.O. nutr. Stud. no. 4.

Garry, R. C., Passmore, R., Warnock, G. M. \& Durnin, J. V. G. A. (1955). Spec. Rep. Ser. med. Res. Coun., Lond., no. 289 .

Hollingsworth, D. F. (1955). Proc. Nutr. Soc. 14, 154.

Insull, W. Jr. (1954). U.S. Army. Med. Nutr. Lab. Rep. no. 146.

Kofranyi, E. \& Michaelis, H. F. (1940). Arbeitsphysiologie, II, 148.

Lehmann, G., Müller, E. A. \& Spitzer, H. (1950). Arbeitsphysiologie, 14, 66.

Medical Research Council: Accessory Food Factors Committee (1945). M.R.C. (War) Memor. no. 14.

Merrill, A. L. \& Watt, B. K. (1955). Agric. Handb. U.S. Dep. Agric. no. 74.

Montoye, H. J., van Huss, W. D., Reineke, E. P. \& Cockrell, J. (1958). Int. Z. angew. Physiol. einschl. Arbeitsphysiol. $\mathbf{1 7}, 28$.

Müller, E. A. \& Franz, H. (1952). Arbeitsphysiologie, 14, 499.

Orsini, D. \& Passmore, R. (195 I). F. Physiol. 1r5, 95.

Passmore, R., Thomson, J. G. \& Warnock, G. M. (1952). Brit. F. Nutr. 6, 253.

Passmore, R. \& Durnin, J. V. G. A. (1955). Physiol. Rev. 35, 80r.

Rankin, A. D., Konishi, F., Insull, W. \& Marcinek, J. (1956). U.S. Army. Med. Nutr. Lab. Rep. no. 188 .

Shephard, R. J. (1955). F. Physiol. r27, 515.

Welch, B. E., Marcinek, J. G., Buskirk, E. R. \& Iampietro, P. F. (1957). U.S. Army. Med. Nutr. Lab. Rep. no. 196.

Wolff, H. S. (1958). F. Physiol. 141, $36 P$. 